\title{
FIBER OPTIC SENSORS FOR ENVIRONMENTAL APPLICATIONS: A BRIEF REVIEW (U)
}

by

J. Rossabi, Environmental Sciences

Westinghouse Savannah River Company

Savannah River Site

Aiken, South Carolina 29808

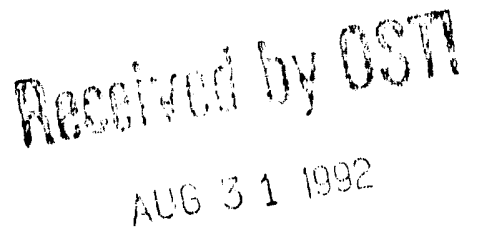

This report was prepared in connection with work done under Contract No. DE-AC09-89SR18035 with the U.S. Department of Energy. By acceptance of this report, the publisher and/or recipient acknowledges the U.S. Government's right to retain a nonexclusive, royalty-free license in and to any copyright covering this report, along with the right to reproduce and to authorize others to reproduce all or part of the copyrighted report. 


\section{DISCLAIMER}

This report was prepared as an account of work sponsored by an agency of the United States Government. Neither the United States Government nor any agency thereof, nor any of their employees, makes any warranty, express or implied, or assumes any legal liability or responsibility for the accuracy, completeness, or usefulness of any information, apparatus, product, or process disclosed, or represents that its use would not infringe privately owned rights. Reference herein to any specific commercial product, process, or service by trade name, trademark, manufacturer, or otherwise does not necessarily constitute or imply its endorsement, recommendation, or favoring by the United States Government or any agency there of. The views and opinions of authors expressed herein do not necessarily state or reflect those of the United States Government or any agency thereof.

This report has been reproduced directly from the best available copy.

Available to DOE and DOE contractors from the Office of Scientific and Technical Information, P.O. Box 62, Oak Ridge, TN 37831; prices available from (615) 576-8401, FTS 626-8401.

Available to the public from the National Technical Information Service, U.S. Department of Commerce, 5285 Port Royal Rd., Springfield, VA 22161. 


\section{FIBER OPTIC SENSORS FOR ENVIRONMENTAL APPLICATIONS: A BRIEF REVIEW (U)}

J. Rossabi, Environmental Sciences

April, 1992

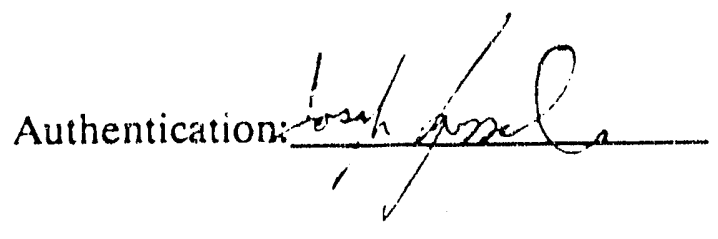

Approved By:

D) 3 rover idedent

D. B. Moore, Section Manager

Environmental Sciences Section

Savannah River Technology Center

WESTINGHOUSE SAVANNAH RIVER COMPANY

SAVANNAH RIVER TECHNOLOGY CENTER

SAVANNAH RIVER SITE

AIKEN, SC 29808

Prepared for the U. S. Department of Energy under Contract No. DE-AC09-89SR18035 


\section{FIBER OPTIC SENSORS FOR ENVIRONMENTAL APPLICATIONS: A BRIEF REVIEW}

\section{SUMMARY}

Understanding the flow and transport of contaminants in the subsurface is vital to a complete knowledge of groundwater quality. This understanding is achieved by measurement of the appropriate chemical and physical subsurface parameters. The ideal measurement woule sccurately assess a parameter without affecting the parameter or its environment. Fiber optic spectroscopy offers some of the most promising techniques for accurate, non-invasive measurements of environmental parameters. Fiber optic sensors for subsurface applications are currently being developed by several Department of Energy laboratories. Some of these sensors have been successfully deployed in the ficld and are attaining the goals of accurate, noninvasive, real time measurements in the subsurface.

\section{INTRODUCTION}

\subsection{Background}

Approximately one half of the population of the United States uses ground water for drinking (Schiffman, 1988). It is therefore important to be able to discriminate and quantify the factors affecting the quality of this resource. Over the past century, much progress has been made in the areas of chemical synthesis and the use of these chemicals in industry and agriculture. Unfortunately, this has not been accompanied by equal progress in the knowledge of the relation between synthetic chemicals and the natural environment. As a result, some of these synthetic chemicals such as organic solvents, pesticides, and herbicides have contaminated otherwise pristine subsurface environments because of improper disposal or application practices. The health risks of some of these contaminants are just beginning to be understood.

Both large, and small, public and private, industrial facilities have been responsible for the introduction of synthetic chemicals into the environment. Department of Energy facilities as well as nearly all other government industrial facilities are included in this group. It is encumbent upon responsible groups to understand, monitor, and control this chemical contamination in the interest of protecting human health and the environment.

Understanding the flow and transport of contaminants in the subsurface is vital to a complete knowledge of ground water quality. Determining contaminant concentration requires chemical analysis. Techniques for the chemical analysis of subsurface contaminants have traditionally relied on the "grab sample" method. In this method, a solid, liquid, or vapor phase sample is obtained at a particular point in the subsurface region and brought into the laboratory for analysis. This method induces many chances for systematic errors, including: the changing of the environment to physically obtain the sample; removal of the sample from its original environment; transportation of the sample in another environment; and analysis in a different environment. All of these may affect the sample or the assessment of the contaminant concentration in that sample. The ideal measurement would accurately assess the contaminant concentration without affecting the contaminart, the sample, or its environment.

\subsection{Optical Spectroscopy}

Since the advent of quantum mechanics, the basic principles of atomic and molecular spectra have not changed (Patterson, 1987). Spectroscopy, the study of spectra, has been used to identify atoms, molecules, and their associated structures and environments. This is done by analyzing the wavelength and intensity of the radiation emitted, absorbed, or scattered by these atoms and molecules under known external electromagnetic conditions (Thorne, 1988). These known external electromagnetic conditions often take the form of a probe wave that is made to interact with the structure of interest.

There are various types of spectroscopic techniques commonly in use. These are categorized according to the characteristics of the probe wave used and the type of interaction between the probe wave and the analyte. Optical spectroscopy uses an electromagnetic wave in the region from the low ultraviolet (less than $200 \mathrm{~nm}$ ) to the far infrared (greater than 10,000 nm) as the probe. The types of interactions 
exploited with optical spectroscopy are of four basic types: absorption, elastic and inelastic scattering, luminescence, and interferometry. All four have been successfully used in chemical analysis.

\subsection{In Situ Measurements}

Although the use of optical spectroscopy for chemical and physical analysis has been well established over the past century it has generally lacked the mability necessary to do analysis outside of a structured laboratory environment. This problem is not limited to optical techniques but is common to most other chemical analytical procedures as well. The problem of analysis in the natural environment, or in situ, is crucial to a more complete undersianding of real world chemical, physical, and biological processes.

Performing chemical analysis requires the isolation of a measurable parameter of interest by controlling the variables associated with that parameter. Analytical techniques achieve this by the selectivily and operational control of the probe and detector as well as by the measurement of ambient conditions such as temperature and pressure. Most analytical techniques require relatively large physical instrumentation and physically stable probes and detectors to accurately make these measurements. Because of the rigidity of the probe and detector configuration, a sisnple must be extracted from its natural environment and brought into the measurement field of the instrument. This changes the parameter's natural conditions and may introduce error in the measurement. In order to make accurate measurements in natural settings, an instrument's presence must minimally affect the measurement yet maintain a useful degree of accuracy. This is often very difficult to achieve because of the physical size limitations requi ed to be noninvasive while maintaining the necessary components to maintain accuracy.

Optical spectroscopy has had the most success of the analytic techniques in making the transition from laboratory to in situ measurement for a number of reasons. One reason is that most optical spectroscopic techniques are non-destructive, which enables relatively continuous measurements. Another reason for its success is the small size and conductivity of waveguides available for the medium. These high conductivity waveguides allow measurements to be made remotely from the probe generation and detection equipment. The small size of the waveguides allows relatively noninvasive measurements to be performed.

Since optical spectroscopy techniques operate by the modulation of a light beam, the sire of the probe is limited only by the minimum diameter of light achievable. Single mode fibers have typical core diameters of 5-10 $\mathrm{\mu m}$. With the progress made in recent years on light sources and optical fibers, probes can be made small enough to be non-intrusive to many of the measurements made of parameters in natural environments.

\section{Fiber Optlc Sensors}

\subsection{Background}

There has been a surge in the field of fiber optic sensor research over the past two decades. This surge has occurred because of progress attained in the field of fiber optic communications reszarch. The communications field is interested in the unadulterated transmission of light signals through plastic or glass optical fiber. However, any unwanted cause of modulation of a communications signal through a fiber has potential as a fiber optic sensirsg parameter.

\subsection{General Sensor Configuration}

The general configuration of an active fiber optic sensing system involves three regions linked by fiber optic waveguides. Passive fiber optic sensors such as those utilizing the chemiluminescent effect do not have a separate optical source and will not be discussed here. The first region consists of an optical source. This can be any source of optical electromagnetic radiation compatible with the waveguide but most often takes the form of a lamp, a light enitting diode (LED), or a laser. The radiation from this source is carried with minimal modulation dowa the first waveguide to a sensing region. This second region is where the 
actual measurement takes place. At this point, the original light signal is modulated. Modulation can be manifested in a change in intensity, frequency, polarization, propagation time, or phase. For example, if a material that characteristically absorbs light over the wavelength range 240 to $260 \mathrm{~nm}$ is placed in the path of the incident radiation, the resultant light will have a lower intensity over that $20 \mathrm{~nm}$ range than if the absorbing material were absent.

The resultant or modulated light passes from the sensing region to the detector region via another fiber optic waveguide. The detector region is the third component of the fiber optic sensor and normally consists of either a photomuitiplier, photodiode, avalanche photodiode, or diode array. The third region often includes a spectrometer ahead of the detector to separate the components of the light by wavelength.

\subsection{Types of Fiber Optic Sensors}

The sensing region of a fiber optic sensor can be either intrinsic or extrinsic. Intrinsic sensing occurs when the light is modulated directly within the fiber. This type of sensor is often used to measure changes in phase by interferometry and is incorporated in fiber optic gyroscopes and other sensors utilizing the Mach. Zender effect (Butler and Ginley, 1988). Extrinsic sensing occurs when light is modulated outside of the ber core region and then reintroduced into the fiber leading to the detection region. This type of sensing is used most often in chemical sensing. Extrinsic modulation can occur in a cell, through a membrane, in a porous region, etc.

Chemical sensing has not been the only fertile region for the application of fiber optic sensors. Fiber optic sensors have been used for a plethora of types of measurements including temperature (Conforti et al., 1989), particle counting (Chow et al., 1988), electric current (Edwards et al., 1989), humidity (Zhou et ai., 1988), clectrochemistry measurements (Kuhn et al., 1990; Van Dyke and Cheng, 1988), and pH measurements (Jones and Porter, 1988; Luo and Walt, 1989a; Gabor and Walt, 1991).

Fiber optic chemical sensors have been used in many different configurations for measuring many different parameters (Seit/, 1984; Peterson, 1988). These sensors have generally used three of the optical spectsoscopic methods discussed above. Interferometric methods have been used most often for the measurement of physical parameters such as rotation, temperature, and strain (Yoshino, 1988) rather than for chemical sensing.

Fluorescence based fiber optic sensors have been exaremely popular for chemical sensing, usually in conjunction with a catalyst or reactant attached to the fiber (Kulp ct al., 1987; Louch and Ingle, 1988; Fuh et al., 1988; Zung et al., 1988; Licberman and Brown, 1988; Herron and Whitchead, 1988; Carrol et al., 1989; Bright and Litwiler, 1989; Luo and Walt, 1989b; Stakhsher and Seitz, 1990; Gunasingham et al., 1990). These types of sensors have also had success in environmental applications such as in situ ground water monitoring (Chudyt et al., 1988), gasoline sensing, hazardous waste screening (Chudyk, 1989), and column experiruents to measure flow and transport (Kulp at al, 1988).

Scattering techniques have also been employed in fiber optic sensors (Laguesse, 1988). Raman scattering probes have been studied most often (Walrafen and Stone, 1972; Ross and McClain, 1981; MeCreery et al ${ }_{\mu}$ 1983; Schwab and McCrecry, 1984; Reichert et al., 1987; Leugers and McLachlan, 1988; Lewis et al, 1988).

Absorption sensing techniques have also been used in fiber optic configurations for chemical sensing (Tenge et al., 1987; Carey et al., 1989; Dickert et al., 1989; Zhou et al., 1989; Renn and Synovec; 1990; Cavinato et al, 1990).

\section{ENVIRONMENTAL FIBER OPTIC CHEMICAL SENSING: Technical Status}

\subsection{Background}

In situ chemical sensing is one of the most important requirements for accurate analysis in the environment as is briefly discussed in section 1.3. However, there bas been a dearth of sensors that are sensitive, precise, and rugged enough to be emplaced in the field. Several fiber optic sensors of 
environmental parameters are described in the following sections. The spectroscopic principles used by these sensors are outlined in the appendix.

Down hole monitoring techniques can be defined as those that are performed at depth in a well. Down hole sensing is differentiated from down hole sampling in that the latter is essentially a grab sample technique that requires analysis of the sample at the surface. Grab sample techniques are appropriate for many environmental measurements but they are subject to the problems associated with that technique listed in section 1.1. Many researchers are currently investigating and refining novel down hole sampling methods.

\subsection{Luminescent/Absorption Sensors}

\subsubsection{Aromathes}

Chudyk et al. have been successful with their down hole, fiber optic fluorescent sensor (Chudyk et al., 1988). The system consists of two optical fibers or fiber bundles that are run down a well. One of the fibers is connected to a laser maintained at the surface. This fiber carries the excitation light from the laser down to the sensing area at the bottom of the well. The other fiber carries the induced fluorescence return signal from the sensing area back to the surface where a detector is maintained. This sensor works well in the detection of aromatic compounds such as benzene, toluene, ethylbenzene, and xylene (BTEX) because of the relatively large optical cross-section of these compounds at wavelengths that are readily transmitted through commercially available fibers. A variation of this sensor has been created which allows detection of cresol isomers and pesticides in the ppb concentration range using laser excited excitation-cmission matrices (Taylor et al, 1991).

The Army Corps of Engineers Waterways Experiment Station (WES) have recently demonstrated two types of fiber optic fluorescent sensors that were designed for use with a cone penetrometer. The cone penetrometer allows access to the subsurface (maximum depth $=290$ feet at the Savannah River Sitc) without drilling a well. One of the fluorescent sensors was developed by WES in collaboration with the Naval Ocean Systems Center (Lieberman et al., 1991a; Andrews and Lieberman, 1991; Lieberman et al., 1991b; Apitz et al., 1992). It uses a pulsed nitrogen laser to generate ultraviolet radiation that is carried down optical fibers to the subsurface. The transmitted light excites a fluorescence emission in petroleum hydrocabon contamination present in the subsurface. This fluorescent signal is then carried back to the surface by a return fiber where it is analyzed using a photodiode array detector and optical multichannel analyıcr system to determine contaminant types and approximate concentration values. The other was developed by Lawrence Linermore National Laboratory and uses a solvatochromic dye coated on an optical fiber (Angel et al., 1991) to monitor for light hydrocarbons.

Pacific Northwest Laboratories (PNL) has cooperated with FiberChem Inc. in the development of a hybrid refractive index/luorescent optrode (Klainer et al., 1988). The sensor has a fluorescent dye fixed on the sensing end of a fiber. This produces an intense return signal at the source/detection end of the fiber when excited by an optical source propagated down the fiber's length. A portion of the circumferential cladding near the sensing end of the fiber has been replaced by a chemical specific reactive coating. Depending on the concentration of the chemical being sensed, the index of refraction of the new coating will change. This results in a difference in the intensity of the returned fluorescent signal detected. Three sensors were designed to detect BTEX, as well as the chlorinated aliphatic organics trichloroethylene (TCE), and carbon tetrachloride $\left(\mathrm{CCl}_{4}\right)$. The BTEX sensor has been commercially marketed under the name Petrosense by FiberChem Inc. and claims a vapor phase detection range of $50 \mathrm{ppmv}$ to $5000 \mathrm{ppmv}$. The TCE sensor has been marketed under the name of Enviroscience, uses a liquid-based chemical reagent method, and claims a dynamic range of less than $1 \mathrm{ppb}$ to greater than $1000 \mathrm{ppm}$ in water or vapor. The operation of this sensor has been demonstrated in the laboratory.

\subsection{Aliphatics}

Aliphatic compounds such as TCE, tetrachloroethylene (PCE), and $\mathrm{CCl}_{4}$ are more difficult to detect than BTEX because they absorb light of a shorter wavelength. Peak absorption of these compunnds 
normally occurs in the low ultraviolet range of the spectrum. This light is more difficult to produce and transmit in intensities necessary for sensitive measurements. Commercially available optical fibers have higher attenuations in the ultraviolet range and are often damaged (solarized) by high intensity light in the low ultraviolet range. Solarization of fibers results in a progressively increasing attenuation of ultraviolet light that is subsequently directed down the damaged fibers. In addition to these problems, the absorption range of aliphatic compounds is often overlapped by the absorption range of natural organic matter such as humic material.

Researchers at Lawrence Livermore National Laboratory have successfully developed and deployed a down hole volatile chlorinated organic sensor (Colston et al., 1992; Milanovich et al, 1986; Angel et al, 1989). This sensor uses a reagent that interacts with the vapor phase concentration of TCE to produce a product with a visible wavelength absorption cross-section that varies with the concentration of TCE in a predictable manner. Because the modulation occurs in the visible wavelength region, it is suitable for low loss transmission over commercially available optical fibers. The instrument has been tested against standard methods and has shown high correlation to these methods. Laboratory sensitivities of the sensor to TCE and chloroform concentrations were below the drinking water standards (less than $1 \mathrm{ppb}$ ) with a dynamic range that spans three orders of magnitude in the vapor phase. In addition a second reagent that allows the instrument to measure TCE over the range $1 \mathrm{ppmv}$ to $500 \mathrm{ppmv}$ has been developed. The sensor has been successfully field tested in a vadose zone well at the Savannah River Integrated Demonstration Sitc. The technology has been commercially licensed to a company manufacturing photolytic processing devices as ancillary equipment. This sensor will be incorporated into the WES cone penetrometer and wiil be tested at the Savannah River Site in May 1992 for rapid, real time chlorinated organic contaminant distribution characterization in the vadose zone. Additional future upgrades include devices that can be placed directly in an aqueous phase, and battery operated, hand-held versions. In its current form, the sensor would not be appropriate for direct emplacement in an aquifer. This is primarily due to the non-reversibility of the reagent used. However, this instrument has been tested at depth in a monitoring well and is the first to demonstrate down hole sensing of TCE with sensitivities better than the drinking water standards.

\subsubsection{Tracers}

Researchers at Savannah River Technology Center (SRTC) have developed a fiber optic probe and field portable diode array spectrophotometer (Van Hare et al., 1989) for measuring ground water flow in the subsurface. Measurements are made by direct absorption sensing of tracer chemicals such as sodium fluorescein or rhodamine. The sensing region is in a screened, flow-through reflectance probe that is buried in the subsurface. Transmitted and modulated light between the source/detector area at the surface and the probe in the aquifer is conducted by two or more optical fibers. The system has been successfully tested in column experiments in the laboratory and will be employed in courdinated groundwater tracer studies to measure subsurface flow and transport parameters at the Savannah River Site later this year. These tracer studies will coordinate several different groundwater flow measurement strategies including in-situ temperature based devices and multi-level sampling devices.

A tlow-through fiber optic probe for tracer dyes has been developed and used by SRTC scientists in experiments to determine bioreactor residence times. The SRTC researchers are also working on fibcr optic $\mathrm{pH}$, nitrate, nitrite, and metal sensors using a fixed reagent on the end of the probe, and a fiber optic Raman sensor. All of these probes are designed to work with the portable dinde array spectrophotometer.

\subsection{Scattering Sensors}

Other direct (no intermediate or reagent) optical techniques, such as Raman spectroscopy or Surface Enhanced Raman (SER) are technologically limited as well. Raman spectroscopy requires an extremely high intensity single mode source, high resolution wavelength separation, and high sensitivity detection systems in order to overcome the problem of very low intensity return signals. SER techniques have not been successfully demonstrated as consistent analytical tools for measuring volatile chlorinated organics in low 
concentrations. Therefore, there have been no successful in situ measurements of volatile chlorinated organic compounds such as TCE and PCE in the aqueous phase by Raman spectroscopy.

Research is currently being done on the use of Raman spectroscopy for detecting pure product in the subsurface (Carrabba et al, 1991b). EIC Laboratories, Inc. has developed a fiber optic Raman spectrometry process that is field portable (Carraba et al., 1988; Carraba et al., 1991a). There is potential for a design linking the Raman system and the cone penetrometer. This system would be able to rapidly screen for dense, non-aqueous phase liquids (DNAPL) without time consuming sample analysis in a laboratory. Both Argonne National Laboratory (AN/L), under a contract, and Oak Ridge National Laboratory (ORNL), under a collaborative agreement, have been working with EIC Laboratories in the development of these fiber optic probes (Carrabba et al., 1991b; Carrabba et al., 1992)

ORNL is al:o working on fiber optic absorption based sensors for environmental applications. Chemical specificity is achieved in this system by derivative ultraviolet absorption (DUVAS) techniques (Hawthorne et al., 1984; Haas, J. W. III, et al., 1991).

\subsection{Interferometric sensors}

An interferometric fiber optic sensor is being developed by Research International Inc. in conjunction with PNL. Sensor systems that can measure pressure, temperature, displacement, refractive index, and gas density (Saaski et al., 1986) have already been produced using this technology. Research International has already produced fiber optic sensors for measuring $\mathrm{pH}$ and hydrogen and will attempt to modify the design of their probe to sense chloroform and $\mathrm{CCl}_{4}$.

\subsection{Conclusion}

In order to make accurate measurements of parameters in natural settings, it is necessary to be as non-invasive, and non-destructive of the natural matrix as possible. An analytical method that measures a parameter in its natural setting is inherently better than one in which the natural matrix is disturbed by the removal of a sample. Because of the complexity and interdependence of parameters in a natural setting, true in situ measurement methods should be a primary goal. Although most of the chemical sensors described above can not yet be permanently emplaced in an aquifer, they are advancing towards the goal of ideal cnvironmental analysis by moving the sensing region below the surface. 
APPENDIX: THEORI

\section{A.1 Optical Spectroscopy}

As mentioned in Section 1.2, there are four basic types of optical spectroscopies currently employed for chemical analysis. These are briefly discussed in the paragraphs following.

\section{A.1.1 Absorption Spectroscopy}

The absorption of electromagnetic energy follows the principles of quantum electrodynamics, however, the process is often adequately described by a semi-classical mechanism (Patterson, 1987). Matter preferentially absorbs light of a particular wavelength range. The wavelength of the light absorbed corresponds to the amount of energy required by the matter to move from a lower energy state to a higher energy state. Quantum dynamic theory specifies the precise wavelength of light necessary to achieve a particular energy state in a unique substance by the Bohr model of the photon.

$$
E=h v
$$

where $E$ is the energy of the photon, $v$ is the frequency of the photon with units $\mathrm{cm}^{-1}$, and $\mathrm{h}$ is Planck's constant.

Within an energy state there are several small vibrational levels of energy or perturbations around the energy state. These various levels have their own individual energy requirements but taken together can be thought of as a continuum around an energy state with very little loss in theoretical accuracy (Janata, 1989). The concept of a continuum allows a statistical treatment of the interaction of light and matter. This treatment leads to the well known Lambert-Beers' equation (Chen, 1987):

$$
\log _{10} \frac{I_{0}}{I}=a b c
$$

where $I$ and $I_{0}$ are the instantaneous and source intensities at a particular wavelength, $a$ is the absorptivity constant of the matter for a given set of conditions, and $\mathrm{b}$ and $\mathrm{C}$ are the path length of the light through the matter and the concentration of the absorbing species in grams/liter (Silverstein et al, 1974). It is useful to define a quantity called the absorbance $A$ of a species as:

$$
A=a b c
$$

A is known as the optical density of a material in the older literature (Silverstein et al., 1974). A plot of the absorbance with respect to wavelength is normally described as the absorbance or absorption spectrum of a chemical species. As is outlined above, the absorption spectrum is dependent on the species type and current energy state and coucentration. 


\section{A.12 Luminescence Spectroscopy}

Matter is usually in its lowest stable energy state for a given ambient condition before the energy of the photon is absorbed. After absorption, the excited matter will again seek its lowest stable energy state. This state is achieved in several ways: chemical or physical transformations of the matter that uses the excess energy, a radiative process in which the energy is lost by the emission of a photon, or a combination of the two processes (Chang, 1971). The wavelength of the radiated photon is dependent on the physical and chemical characteristics of the matter. The radiative processes give rise to the field of luminescence spectroscopy, which includes both fluorescence spectroscopy commonly used in liquid chromatography apparatus for liquid analysis, and photoluminescence spectroscopy, which is often used to characterize crystal purity in semiconductor materials (Goldberg and Weiner, 1989).

\section{A.1.3 Interferometry}

Interferometric sensors measure the interference pattern produced when two or more beams of light, usually of different phases, are combined (Baird, 1990). Phase differences normally result from differing path lengths of the two beams. The path length of a beam is determined by the characteristics of the medium, such as chemical type or concentration, that it is traveling through.

\section{A.1.4 Scattering Processes}

The last process mentioned is scattering. Radiative scattering is a process involving the interaction of the wave and momentum vectors of the light and matter (Gilson and Hendra, 1970). This interaction gives rise to scattered radiation that is characteristically different than the incident radiation. The differences can be in wavelength, intensity, polarization, and coherence, and are dependent on the type of matter and the characteristics of the incident intensity. Scattering processes are usually probed with an incident beam of monochromatic light and are differentiated by the resultant scattered light's wavelength spectrum with respect to the incident spectrum. These processes include Rayleigh, Brillouin, and Raman scattering. Of these three, Raman scattering has been the most useful in the optical analysis of matter.

\section{A.2 Filser Optic Waveguides}

The theory behind the transmission of light down a fiber waveguide harkens back to the classical Maxwell's Equations describing electromagnetic fields and Snell's law (Olsen and Rogers, 1984). Snell's law is usually written as:

$$
n_{1} \sin \theta_{1}=n_{2} \sin \theta_{2}
$$

where $n_{1}$ and $n_{2}$ are the indices of refraction of two adjoining unedia, and $\theta_{1}$ and $\theta_{2}$ are the angles of incidence and reflection measured with respect to the perpendicular to the interfacial surface of a ray of light passing from medium 1 to medium 2 .

where:

For $n_{1}$ greater than $n_{2}$, if the angle of incidence, $\theta_{1}$ is greater than the critical angle defined as $\theta_{c}$

$$
\sin \theta_{c}=\frac{n_{2}}{n_{1}}
$$


nearly all of the light will be reflected back into medium 1. If medium 1 is formed as a cylinder concentric to a larger cylinder of medium 2, it is easy to see that light introduced at one end of medium 1 will traverse down the length of medium 1 by multiple internal reflections. The light is therefore guided from one end to the other.

Optical fiber is usually fabricated from glass or plastic preforms and is drawn into long thin strands serving as the primary light conduit or cot $t$. These strands are normally coated with a cladding material of a different index of refraction than the core material to maintain the waveguiding propertics of the core.

Other layers are also coated on to improve properties such as strength and flexibility of the fiber optic cable. The transmission properties of the fiber depend on the core and cladding materials and their relation (Daly, 1984). Fiber optic materials and manufacturing methods are rich topics but are beyond the scope of this report. 


\section{REFERENCES}

Andrews, J. M. and Lieberman, S. H. (1991). Use of a Neural Network for the Analysis of Fluorescence Spectra from Mixtures of Polycyclic Aromatic Hydrocarbons. In Lieberman, R. A., (Ed.), Chemical, biochemical, and envirommental fiber sensors III (pp.30-38). Bellingham, WA: Procecdings SPIE 1587.

Angel, S. M., Anderson, ?. L., and Langry, K. (1991). Simple reversible fiber-optic chemical sensors using solvatochromic dyes. In press Procecdings of SPIE OE/Fibers \%1. Chemical, Biochemical, and Environmental Fuer Sensors III, vol. 1587-15, Boston, MA.

Angel, 3. M., Ridley, M. N., Langry, K., Kulp, T. J., and Myrick, M. L. (1989). New Developrnents and Applicatio us of Fiber-Optic Sensors. In R. W. Murray, R. E. Dessey, W. R. Heineman, J. Janata, and W. R. Seitz (Eds.), American Chemical Socicty Symposium Series 403 (pp 345-363). Washington, D.C.: American Chemical Society.

Apitz, S. E., Theriault, G. A., and Lieberman, S. H. (1992). OPtimization of the optical characteristics of a bier-optic guided laser fluorescence technique for the in situ evaluation of fuels in soils. In Vo-Dinh, T. (Ed.), Environmental Process and Tecatment Technologies (in press). Bellingham, WA: Proceedings SPIE 1637, presented at OE/LASE "92, January 1992, Los Angeles, CA.

Baird, K. M. (1990). Interferometers and Interferometry In R. C. Lerner and G. L. Trigg (Eds.), Encyclopedia of Physics (pp 546-548). New York: VCK Publishers, Inc..

Bright, F. V., and Litwiler, K. S. (1989). Multicomponent fuorometric analysis using a fiber-optic probe. Analytical Chemistry, 61, 1510-1513.

Butler, M. A., and Ginley, D. S. (1988). Hydrogen sensing with palladium-coated optical fibers. Journal of Applied Physics, 64, 3706-3712.

Carey, W. P., DeGrandpre, M. D., and Jorgensen, B. S. (1989). Polymer-coated cylindrical waveguide absorption sensor for high acidities. Analytical Chemistry, 61, 1674-1678.

Carrabba M. M., Edmonds, R. B., Marren, P. J., and Rauh, R. D. (1988). The Suitability of Surface Enhanced Raman Spectroscopy (SERS) To Fiber Optic Chemical Sensing of Aromatic Hydrocarbon Contamination in Groundwater. Proceedings of the First International Symposium: Field Screening Methods for Hazartous Waste Site Invertigations, Oct. 11-13, 31-40.

Carrabba M. M., Spencer, K. M., and Rauh, R. D. (1991a). Compact Raman instrumentation for process and environmental monitoring. Procedings of the SPIE: Environmental Sensing and Combustion Diagnostics, 134, Jan. 24-25, 127-134.

Carrabba M. M., Edmonds, R. B., Rauh, R. D., and Haas, J. W. III (1991b). Spectroelectrochemical Sensing of Chlorinated Hydrocarbons for Fienld Screening and In Situ Monitoring Applications. Presenced_at the Second International Symposium: Field Screening Methods for Hazardous Wastes and Toxic Chemicals, Las Vegatas, NV, Feb. 12-14.

Carrabba M. M., Spencer, K. M., Edmonds, R. B., Rauh, R. D., and Haas, J. W. III (1992). Spectroclectrochemical lechmologies and instrumentation for environmental and process monitoring. 
Presented at the SPIE: Environmental and Process Monitoring Tehenologies, NV, Feb. 12-1637.

Carroll, M. K., Bright, F. V., and Hieftje, G. M. (1989). Fiber-optic time-resolved fluorescence sensor for the simultaneous determination of $\mathrm{Al}^{3+}$ and $\mathrm{Ga}^{3+}$ or $\mathrm{In}^{3+}$. Analytical Chemisiry, 61, 1768-1772.

Cavinato, A.G., Mayes, D.M., Ge, Z, and Callis, J.B. (1990). Noninvasive method for monitoring ethanol in fermentation processes using fiber-optic near-infrared spectroscopy. Analytical Chemistry, 62, 1977 1982.

Chang, R. (1971). Basic Principles of Spectroscopy. Ncw York: McGraw-Hill Book Co..

Chen, H-L. (1987). Applications of laser absorption spectroscopy. In Radziems'i, L. J., Solarz, R. W., and Paisner, J. A. (Eds.), Laser spectroscepy ind irs applicatiosus (pp. 261-350). New York: Marcel Dekker, Inc.

Chow, K. M., Stansfield, M. G., Carr, R. J. G., Rarity, J. G., and Brown, R. G. W. (1988). On-line photon

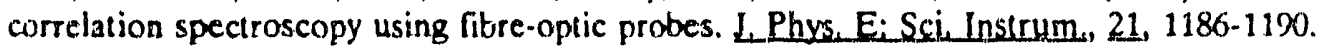

Chudyk, W., Pohlig, K., Rico, N., and Johnson, G. (1988). Ground water monitoring using laser fluorescence and liber optics. In Lieberman, R. A., and Wlodarczyk, M. T. (Eds.), Chemical, biochemical.and cnvironmental applications of ribers (pp.45-47). Bellingham, WA: Proceedings SPIE 990.

Chudyk, W. (1989). Field screening of hazardous waste sites. Environmental_Science_and Technolory, 23, 504-507.

Colston, B. W., Brown, S. B., Langry, K., Daley, P. F., and Milannvich, F. P. (1992). Fiber Optic Sensor for Continuous Monitoring of Chlorinated Hydrocarbons. Requested for publication by Talanta.

Conforti, G., Brenci, M., Mencaglia, A., and Mignani, A. G, (1989). Fiber-optic thermometric probe utilizing GRIN lenses. Applied Opliss, 28, 577-580.

Daly, J. C. (1984). Introduction. In Daly, J. C. (Ed.), Fiber Optiss (pp. 1-20). Boca Raton, Fla: CRC Press Ins.

Dickert, F. L, Schreiner, S. K., Mages, G. R, and Kimmel, H. (1989). Fiber-optic dipping sensor for organic solvents in wastewater. Analutical Chemistry, 61, 2306-2309.

Edwards, H. O., Jedrzejewski, K. P., Laming, R. I, and Payne, D. N. (1989). Optical design of optical fibers for electrical measurement. Applied Optiss, 28, 1977-1979.

Fuh, M-R. S. Burgess, L. W., and Christian, G. v.(1988). Single fiber-optic fuorescence enzyme-based sensor. Analvical Chemistry, 60, 433-435.

Gabor, G. and Walt, D. R. (1991). Sensitivity enhancement of fluoresecent pH indicators by inner filter effects. Analutical Chemisury, 63, 793-796.

Gilson, T. R. and Headra, P. J. (1970). Laser-Raman Spectroscopy. London, U.K.: Wiley-Interscience.

Goldberg, M. C., Weiner, E. R. (1989). Introduction. In M. C. Goldberg (Ed.), Luminescence Apolications in Biolerjal. Chemical. Environmental and Hudrological Scienses. A.C.S. Symposium Series 383 (pp. 1-22). Washington, D.C.: American Chemical Society. 
Gunasingham, H., Tan, C., and Seow, J. K. L. (1990). Fiber-optic glucose sensor with electrochemical geveration of indicator reagent. Analutical Chemistry, 62, 755-759.

Haas, J. W. III, Matthews, T. G., and Gammage, R. B. (1991). In Situ Detection of Toxic Aromatic Compounds in Groundwater Using Fiber Optic UV Spectroscopy. In roseedings of the Second International Symposium on Field Screenine Methods for Hazardous Wastes and Texic Chemicals (pp.677-682). EMSL, Las Vegas, NV, 12-14 February 1991.

Hawthorne, A. R., Morris, S. A., Moody, R. L., and Gammage, R. B. (1984). DUVAS as a real-time, lieldportable wastemonitor for phenolics. Journal of Environmental Science and Health, A19(3), 253-266.

Herron, N. R. and Whitehead, D. W. (1988). Evolution of a fiber-optic chemical fluorescence sensor for monitoring dissolved volatiles. In Lieberman, R. A., and Wlodarczyk, M. T. (Eds.), Chemical biochemical and environmenlal apolications of fibers (pp.37-44). Bellingham, WA: Proceedings SPIE 990.

Janata, J. (1989). Principles of Chemical Sensors, New York: Plenum Press.

Junes, T. P., and Porter, M. D. (1988). Optical pHI sensor based on the chemical modification of a porous polymer film. Analutical Chemistry, 60, 404-406.

Karstang, T. V., and Kvalheim, O. M. (1991). Multivariate prediction and background correction using local modeling and derivative spectroscopy. Analutical Chemistry, 63, 767-772.

Klainer, S. M., Dandge, D. K., Goswami, K., Eccles, L. A., and Simon, S. J. (1988). A Fiber Optic Chemical Sensor (FOCS) For Monitoring Gasoline. Environmental Monitoring Systems Laboratory, U.S.E.P.A. Document EPA/600/X-88/259, June 1988.

Kuhn, L. S., Weber, A., and Weber, S. G. (1990). Microring electrode/optical waveguide: electrochemical characterization and application to clectrogenerated chemiluminescence. Analytical Chemistry, 62 $1631-1636$.

Kulp, T. J., Camins, I., Angel, S. M., Munkholm, C., and Walt, D. R. (1987). Polymer immobilized enzyme optrodes for the detection of penicillin. Analytical Chemistry, 52, 2849.2853.

Kulp, T. J., Bishop, D, and Angel, S. M. (1988). Column-profile measurements using fiber-optic spectroscopy. Soil Science Society of America Journal, 52, 624-627.

Laguesse, M. (1988). An optical fibre refractometer for liquids using two measurement channels to reject optical attenuation. L. Phys, E: Sci.Instrum. 21, 64-67.

Leugers, M. A. and McLachlan, R. D. (1988). Remote analysis by fiber optic raman spectroscopy. In Lieberman, R. A., and Wlodarczyk, M. T. (Eds.), Chemical, biochemical and environmental applications of fibers (pp.88-95). Bellingham, WA: Proccedings SPIE 990.

Lewis, E. N., Kalasinsty, V. F, and Levin, I. W. (1988). Near-infrared fourier transform raman spectroscopy using fiber-optic assemblies. Analutical Chemistry, 60, 2658-2661.

Lieberman, R. A., and Brown, K. E. (1988). Intrinsic fiber optic chemical sensor based on two-stage fluorescence coupling. In Lieberman, R. A., and Wlodarczyk, M. T. (Eds.), Chemical, biochemical and environmental applications of fibers (pp.104110). Bellingham, WA: Proceedings SPIE 990. 
Lieberman, S. H., Theriault, G. A., Coopsr, S. S., Malone, P. G., Olsen, R. S., and Lurk, P. W. (1991a). Rapid, Subsurface, In Situ Field Screening of Petroleum Hydrocarbon Contamination Using Laser Induced Fluorescence Over Optical Fibers. In Second International Symposium - Field Screening Methods for Hazardous Wastes and Toxic Chemicals (pp.57-63). Las Vegas, NV: Symposium Proceedings 12-14 February 1991.

Lieberman, S. H., Inman, S. M., and Theriault, G. A. (1991b). Laser-Induced Fluorescence Over Optical Fibers for Real-Time In Situ Measurement of Petroleum Hydrocarbons in Seawater. In Proceedings Oceans '21 Vol.I (pp.509-514). Honolulu, HI: Proceedings 1-3 October 1991.

Louch, J., and Ingle, J. D. (1988). Experimental comparison of single- and double-fiber configurations for remote fiber-optic fluorescence sensing. Analytical Chemistry, 60, 2537-2540).

Luo S., and Walt, D. R. (1989a). Fiber-optic sensors based on reagent delivery with controlled-release polymers. Analutical Chemistry, 61, 174177.

Luo S., and Walt, D. R. (1989b). Avidin-biotin coupling as a general method for preparing cnzyme-based fiber-optic sensors. Analytical Chemistry. 61, 1069-1072.

McCrecry, R. L., Fleischmann, M., and Hendra, P. (1983). Fiber optic probe for remote raman spectroscopy. Analnical Chemintiry, 55, 146-148.

Milanovich, F. P., Garvis, D. G., Angel, S. M., Klainer, S. K., and Eccles, L. (1986). Remote detection of organochlorides with a fiber optic based sensor. Anal. Inst, 15, 137-147.

Niclsen, J. M., Pinder, G. F., Kulp, T. J., and Angel, S. M. (1991). Investigation of dispersion in porous media using fiber-optic technology.Water Resources Research, 27, 2743-2749.

Olsen, R. G., and Rogers, D. A. (1984). Propagation in optical fibers. In Daly, J. C. (Ed.), Fiher ()ntics (pp. 51-79). Boca Raton, Fla: CRC Press Inc.

Patterson, C. W. (1987). Semiclassical principles of atomic and molecular spectra. In Radziemski, L. J., Solarz, R. W. and Paisner, J. A. (Eds.), Laser spectrescopy and its applications (pp. 1-90). Ncw York: Marcel Dekker, Inc.

Peterson, J. I. (1988). Fiber optic chemical sensor development. In Lieberman, R. A., and Wlodarczyk, M. T. (Eds.), Chemical biochemical and environmental applications of fibers (pp.2-17). Bellingham, WA: Proceedings SPIE 990.

Reichert, W. M., Ives, J. T., and Suci, P. A. (1987). Emission spectroscopy utilizing an air-cooled argon laser and an optrode-based UV-Vis spectrophotometer: A scaled-down laser spectroscopy configuration for solution-phase fiber optic sensing. Applied Spectroscopy 4 41, 1347-1350.

Renn, C. N. and Synovec, R. E. (1990). Single optical fiber, position-sensitive detector-based multiwavelength absorbance spectrophotometer. Analytical Chemistry, 62, 558-564.

Ross, H. B. and MicClain, W. M. (1981). Liquid core optical fibers in raman spectroscopy. Applied Spectroscopy, 35,439-442.

Saaski, E. W., Harth, J. C., Mitchell, G. L. (1986). A Fiber Optic Sensing System Based on Spectral Modulation. ISA Proceedings Advances in Instrumentation, 41, Part 3, 1177-1184. 
Schiffman, A. (1988). Ground-water contamination -- a regulatory framework. Ground Water, 26, 554-558.

Schwab, S. D., and McCreery, R. L. (1984). Versatile, efficient raman sampling with fiber optics. Analytical Chemistry, 56, 2199-2204.

Seitz, W. R. (1984). Chemical sensors based on fiber optics. Aralytical Chemistry, 56, 16A-34A.

Shakhsher, Z. M. and Seitz, W. R. (1990). Optical detection of cationic surfactants based on ion pairing with an environment-sensitive fluorophor. Analytical Chemistry, 62, 1758-1762.

Silverstein, R. M., Bassler, G. C., and Morril, T. C. (1974). Spectrometric Identification of Organic Compounds (3rd ed.). New York: John Wiley and Sons.

Taylor, T. A., Xu, H., and Kenny, J. E. (1991). Laser Fluorescence EEM Instrument For In Situ Groundwater Screening. In Proceedings of the Second International Symposium on Field Scrcening Methods for Hazardous Wastes and Texic Chemicals (pp.797-804). EMSL, Las Vegas, NV, 12-14 February 1991.

Tenge, B., Buchanan, B. R., and Honigs, D. E. (1987). Calibration in the fiber optic region of the nearinfrared. Applied Spectroscopy, 41, 779-785.

Thorne, A. P. (1988). Spectrophysiss (2nd ed.). New York: Chapman and Hall.

Van Hare, D. R., O'Rourke, P. E., Prather, W. S., Bowers, M. B., and Hovanec, M. J. (1989). Online FiberOptic Spectrophotometry. Internal Document DP-MS-88-186, E.I. du Pont de Nemours and Company for the Department of Energy.

Van Dyke, D. A., and Cheng, H-Y (1988). Fabrication and characterization of a fiber-optic-based spectrocicctrochemical probe. Analytical Chemistry, 60, 1256-1260.

Walrafen, G. E., and Stone; J. (1972). Intensification of spontancous raman spectra by use of liquid corc optical fibers. Applied Spectroscopy, 26, 585-589.

Yoshino, T. (1988). Heterodyne technology for Optical Sensors. Optical Fiber Sensors. 1988 Technical Digest Series. Vol. 2 pp 40-43, Washington, D.C.: Optical Society of America.

Zhou, Q, Shahriari, M. R., Krita, D., and Sigel, G. H. (1988). Porous fibet-optic snesor for high-sensitivity humidity measurements. Analytical Chemistry, 60, 2317-2320.

Zhou, Q., Kritz, D., Bonnell, L., and Sigel, G. H. (1989). Porous plastic optical fiber sensor for ammonia measurement. Applied Optics, 28, 2022-2025.

Zung, J. B., Woodlee, R. L., Fuh, M-R. S., Warner, I. M. (1988). Fiber optic based multidimensional fluorometer for studies of marine pollutants. In Lieberman, R. A., and Wlodarczyk, M. T. (Eds.), Chemical biochemical, and environmental applications of fibers (pp.49-54). Bellingham, WA: Proceedings SPIE 990. 

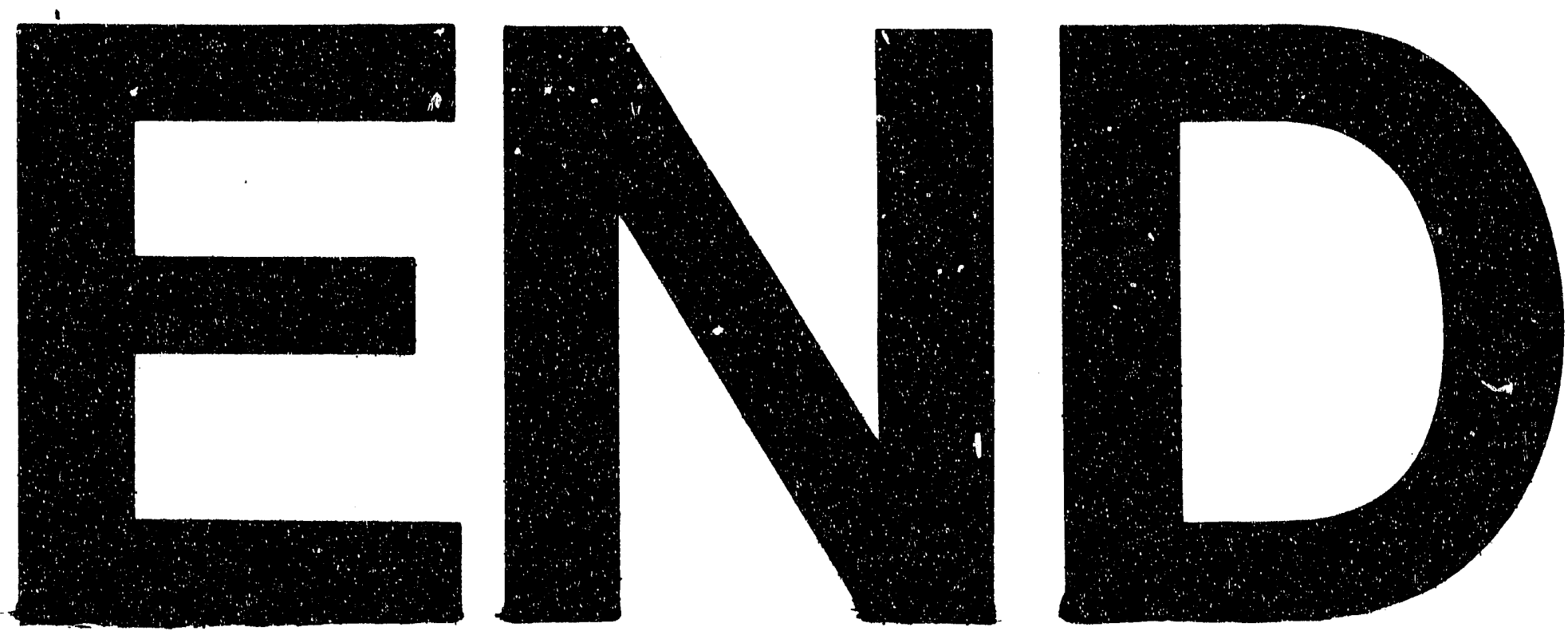

.

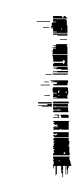
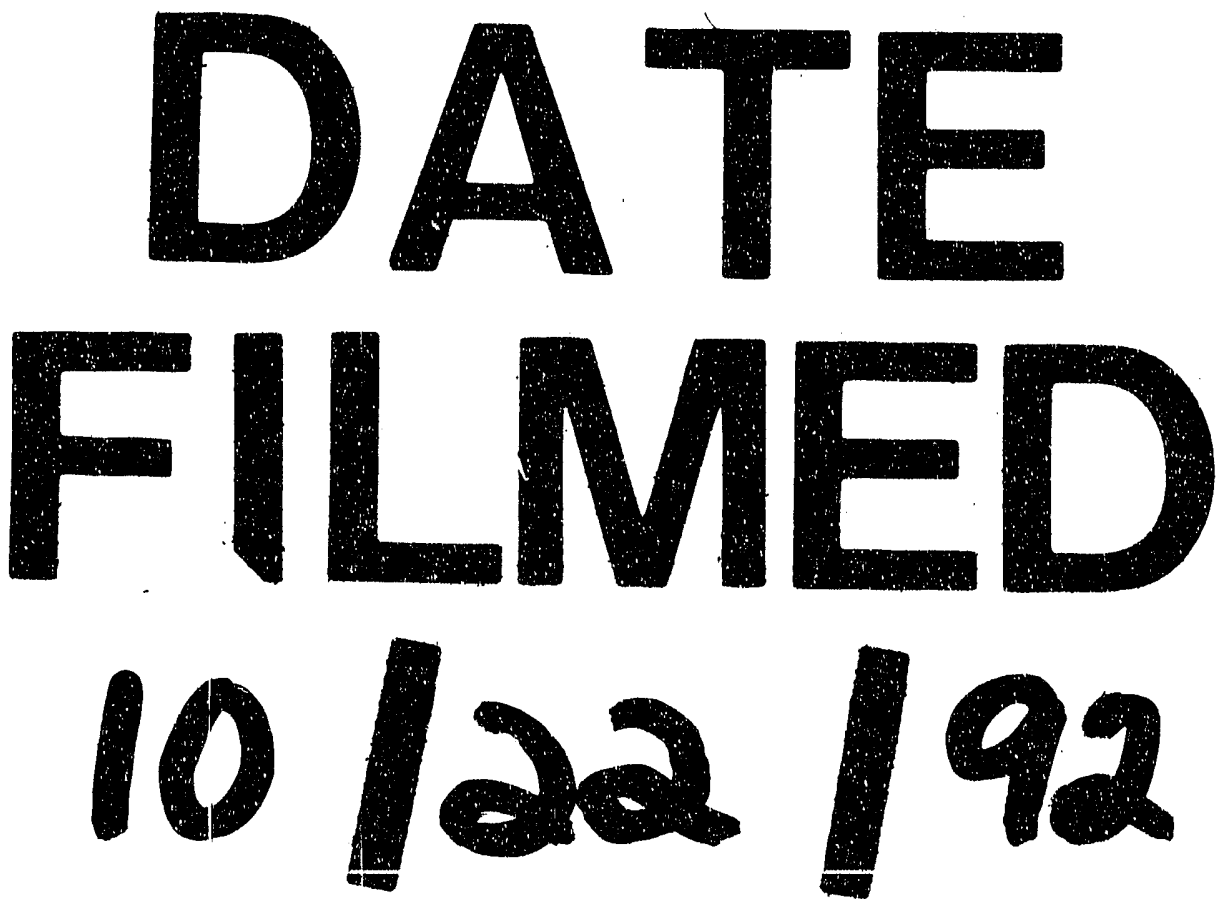
